
neuronal mitochondrial dynamics?

\author{
Andrea C. Paula-Lima ${ }^{1,2,3 *}$ and Cecilia Hidalgo ${ }^{2,3,4}$ \\ 1 Faculty of Dentistry, Department of Basic and Communitarian Sciences, Universidad de Chile, Santiago, Chile \\ ${ }^{2}$ Centro de Estudios Moleculares de la Célula, Universidad de Chile, Santiago, Chile \\ ${ }^{3}$ Biomedical Neuroscience Institute, Universidad de Chile, Santiago, Chile \\ ${ }^{4}$ Physiology and Biophysics Program, Faculty of Medicine, Institute of Biomedical Sciences, Universidad de Chile, Santiago, Chile \\ *Correspondence: apaula@med.uchile.cl
}

Edited by:

Dieter Wicher, Max Planck Institute for Chemical Ecology, Germany

\section{A commentary on}

Canonical Wnt signaling protects hippocampal neurons from $A \beta$ oligomers: role of non-canonical Wnt-5a/Ca ${ }^{2+}$ in mitochondrial dynamics

by Silva-Alvarez, C., Arrazola, M. S., Godoy, J. A., Ordenes, D., and Inestrosa, N. C. (2013). Front. Cell Neurosci. 7:97. doi: 10.3389/fncel.2013.00097

Alzheimer's disease (AD) is the most common form of dementia in the elderly (Querfurth and Laferla, 2010). Recent evidence indicates that soluble neurotoxic $\mathrm{A} \beta$ oligomers (A $\beta \mathrm{Os}$ ) play a causative role in $\mathrm{AD}$ pathogenesis, since they accumulate in the brain of affected individuals and bind specifically to excitatory synapses, prompting changes in their composition, shape, and density (Paula-Lima et al., 2013). These toxic effects presumably underlie the loss of neuronal connectivity characteristic of $\mathrm{AD}$ (Ferreira and Klein, 2011). In primary hippocampal neurons, $\mathrm{A} \beta \mathrm{O}$ s induce $\mathrm{Ca}^{2+}$ entry through N-Methyl-D-aspartate (NMDA) receptors and promote reactive oxygen species (ROS) generation (De Felice et al., 2007). The ensuing increase in postsynaptic $\mathrm{Ca}^{2+}$ and ROS levels promotes $\mathrm{Ca}^{2+}$ release from the endoplasmic reticulum

Abbreviations: AD, Alzheimer's disease; AMPK, AMP-activated protein kinase; $A \beta$, amyloid- $\beta$ peptide; $\mathrm{A} \beta \mathrm{O}$, difusible $\mathrm{A} \beta$ oligomers; CaMKI $\alpha$, calcium/calmodulin-dependent protein kinase $\mathrm{I} \alpha$; CAMKK2, calcium/calmodulin-dependent protein kinase 2; Drp1, Dynamin-related protein; ER, endoplasmic reticulum; IP3, inositol 1,4,5-trisphosphate; LTP, long-term potentiation; NMDA, N-methyl-Daspartate glutamate; PKC, protein kinase C; PLC, Phospholipase C; ROS, reactive oxygen species; RyR, Ryanodine Receptor; SERCA, sarco/endoplasmic reticulum $\mathrm{Ca}^{2+}$-ATPase.
(ER) via joint stimulation of the ER redox-sensitive ryanodine receptor (RyR) channels (Paula-Lima et al., 2011). The resulting unusually long-lasting $\mathrm{Ca}^{2+}$ signals prevent the dendritic spine remodeling induced by brain-derived neurotrophic factor, among other effects (Paula-Lima et al., 2011). Additionally, a previous report indicated that $\mathrm{A} \beta \mathrm{O}$ induced $\mathrm{Ca}^{2+}$ release causes ER stress, oxidative damage, and cell death (Resende et al., 2008).

Abnormal mitochondrial function likely plays an important role in $\mathrm{AD}$ (Lin and Beal, 2006; Cho et al., 2010; Manji et al., 2012; Itoh et al., 2013). Current studies have demonstrated the existence of mitochondrial-ER contact sites, originating microdomains of localized $\mathrm{Ca}^{2+}$ signal generation (Csordas et al., 2010). Mitochondria operate either as a barrier $\mathrm{Ca}^{2+}$ buffer or as facilitating factors in the spreading of $\mathrm{Ca}^{2+}$ signals to the nucleus (Alonso et al., 2006). Mitochondria are highly dynamic structures, which in live neurons divide, fuse, and move within axons and dendrites (Cheng et al., 2010). We have reported that the long-lasting $\mathrm{Ca}^{2+}$ signals generated by $\mathrm{A} \beta \mathrm{O}$ s in primary hippocampal neurons disrupt mitochondrial network structure; suppressing RyR activity by pre-incubation with inhibitory ryanodine prevents A $\beta O$ s-induced mitochondrial fission, indicating that this process requires the RyR-mediated $\mathrm{Ca}^{2+}$ signals generated by A $\beta O s$ (Paula-Lima et al., 2011). Direct activation of RyR-mediated $\mathrm{Ca}^{2+}$ release by the RyR agonist 4-chloro methyl cresol promotes mitochondrial network fragmentation in primary hippocampal neurons, further indicating that RyR activation promotes mitochondrial fission (Sanmartin et al., 2012). Of particular relevance in this regard are recent reports showing that increased mitochondrial network fission occurs in neurodegenerative diseases and diabetes (Yoon et al., 2011; Itoh et al., 2013).

The work by Silva-Alvarez and colleagues confirms that RyR inhibition with ryanodine prevents the alterations in mitochondrial morphology induced by A $\beta O s$. They also show that pre-incubation of primary hippocampal neurons with $\mathrm{A} \beta \mathrm{O}$ s plus thapsigargin, an irreversible inhibitor of the sarco/endoplasmic reticulum $\mathrm{Ca}^{2+}$-ATPAse (SERCA), causes irreversible mitochondrial fragmentation, suggesting that both RyR and SERCA contribute to the loss of $\mathrm{Ca}^{2+}$ homeostasis induced by A $\mathrm{AOs}$ (Silva-Alvarez et al., 2013). An alternative explanation would be, however, that the permanent ER depletion produced by SERCA inhibition with thapsigargin contributes to the irreversible mitochondrial fragmentation produced by A $\beta$ Os. According to Silva-Alvarez et al. (2013), the mitochondrial fragmentation promoted by $\mathrm{A} \beta \mathrm{O}$ s may involve $\mathrm{Ca}^{2+}$-dependent activation of signaling pathways that promote mitochondrial fission, as detailed below.

An important new finding presented by Silva-Alvarez et al. (2013) is that activation of Wnt signaling by the non-canonical Wnt-5a ligand prevents the RyR-mediated mitochondrial fragmentation induced by A $\beta$ Os. Previous work from these and other authors have implicated Wnt signaling in synaptic plasticity, in modulation of long-term potentiation (LTP) (Cheng et al., 2010; Cerpa et al., 2011) and in 
neuroprotection (Toledo et al., 2008). In their current report, Silva-Alvarez and colleagues show that activation of Wnt-5amediated signaling protects neurons from $\mathrm{A} \beta \mathrm{O}$ s toxicity, preventing the increased mitochondrial fission and the Bcl-2 exposure to the mitochondrial outer membrane caused by A $\beta O$ s (Silva-Alvarez et al., 2013). Based on their unpublished results, these authors further propose that noncanonical Wnt signaling induced by Wnt5a inhibits mitochondrial fission via a mechanism that involves $\mathrm{Ca}^{2+}$ release from the ER. To explain their results, Silva-Alvarez et al. (2013) propose that Wnt-5a binding to its Frizzled receptor activates Dishevelled, which in turn would activate a signaling cascade involving a trimeric $G$ protein, phospholipase C (PLC), and generation of inositol 1,4,5trisphosphate $\left(\mathrm{IP}_{3}\right)$, which increases intracellular $\mathrm{Ca}^{2+}$ by promoting $\mathrm{IP}_{3}$-receptor mediated $\mathrm{Ca}^{2+}$ release from the ER. Through $\mathrm{Ca}^{2+}$-induced $\mathrm{Ca}^{2+}$ release, the ensuing $\mathrm{Ca}^{2+}$ increase would promote RyR-mediated $\mathrm{Ca}^{2+}$ release, generating $\mathrm{Ca}^{2+}$ signals that activate $\mathrm{Ca}^{2+}$-dependent kinases such as PKC and CaMKI $\alpha$, or the phosphatase calcineurin, which would affect mitochondrial dynamics via activation of Dynamin-related protein (Drp1), a protein critically involved in mitochondrial fission (Smirnova et al., 2001; Qi et al., 2011). In fact, some evidence implicates activation of these enzymes by $\mathrm{A} \beta \mathrm{O}$ s-generated $\mathrm{Ca}^{2+}$ signals. Thus, inhibition of the PKC pathway reduces the cell death induced by $\mathrm{A} \beta \mathrm{O}$ (Kriem et al., 2005) while inhibition of a pathway engaging CAMKK2-AMPK-Tau prevents the synaptotoxic effects of A $\beta O$ s (MairetCoello et al., 2013); additionally, calcineurin activation mediates the synaptic defects and memory disruption induced by A $\beta$ Os (Reese and Taglialatela, 2011). Moreover, we reported that $\mathrm{A} \beta \mathrm{O}$ s promote Drp-1 translocation to the mitochondria in primary hippocampal neurons; this translocation does not occur following inhibition of RyR-mediated $\mathrm{Ca}^{2+}$ release (Paula-Lima et al., 2011). Therefore, $\mathrm{Ca}^{2+}$ signaling, and in particular RyR-mediated $\mathrm{Ca}^{2+}$-release, plays a critical role in the fragmentation of mitochondrial network induced by $A \beta O s$. Overall, the work of Silva-Alvarez et al. (2013) indicates that $\mathrm{Ca}^{2+}$ release from the ER lies downstream of the non-canonical Wnt-5a ligand binding to its receptor.

Although AD pathogenesis has been extensively studied over the last 100 years, no curative or preventive treatments are available at present for effective patient treatment. Many efforts have been made to establish new targets to counteract the deleterious effects of $\mathrm{A} \beta \mathrm{O}$ s on neuronal function. The beneficial effects of Wnt-5a signaling against the mitochondrial network damage induced by $\mathrm{A} \beta \mathrm{O}$ s reported by Silva-Alvarez et al. (2013) raises a new approach to counteract the aberrant $\mathrm{Ca}^{2+}$ signals induced by A $\beta O s$. Thus, the Wnt-5a signaling pathway might constitute a possible target for the development of new therapeutic treatments for AD.

\section{ACKNOWLEDGMENTS}

The study was supported by: FONDECYT 11110322, FONDECYT 1100052, and BNI P-09-015.

\section{REFERENCES}

Alonso, M. T., Villalobos, C., Chamero, P., Alvarez, J., and Garcia-Sancho, J. (2006). Calcium microdomains in mitochondria and nucleus. Cell Calcium 40, 513-525. doi: 10.1016/j.ceca. 2006.08.013

Cerpa, W., Gambrill, A., Inestrosa, N. C., and Barria, A. (2011). Regulation of NMDA-receptor synaptic transmission by Wnt signaling. J. Neurosci. 31, 9466-9471. doi: 10.1523/JNEUROSCI.631110.2011

Cheng, A., Hou, Y., and Mattson, M. P. (2010). Mitochondria and neuroplasticity. ASN Neuro. 2:e00045. doi: 10.1042/AN20100019

Cho, D. H., Nakamura, T., and Lipton, S. A. (2010). Mitochondrial dynamics in cell death and neurodegeneration. Cell. Mol. Life Sci. 67, 3435-3447. doi: 10.1007/s00018-010-0435-2

Csordas, G., Varnai, P., Golenar, T., Roy, S., Purkins, G., Schneider, T. G., et al. (2010). Imaging interorganelle contacts and local calcium dynamics at the ER-mitochondrial interface. Mol. Cell 39, 121-132. doi: 10.1016/j.molcel. 2010.06.029

De Felice, F. G., Velasco, P. T., Lambert, M. P., Viola, K., Fernandez, S. J., Ferreira, S. T., et al. (2007). Abeta oligomers induce neuronal oxidative stress through an N-methyl-D-aspartate receptor-dependent mechanism that is blocked by the Alzheimer drug memantine. J. Biol. Chem. 282, 11590-11601. doi: 10.1074/jbc.M607 483200

Ferreira, S. T., and Klein, W. L. (2011). The Abeta oligomer hypothesis for synapse failure and memory loss in Alzheimer's disease. Neurobiol. Learn. Mem. 96, 529-543. doi: 10.1016/j.nlm.2011.08.003

Itoh, K., Nakamura, K., Iijima, M., and Sesaki, H. (2013). Mitochondrial dynamics in neurodegeneration. Trends Cell Biol. 23, 64-71. doi: 10.1016/j.tcb.2012.10.006
Kriem, B., Sponne, I., Fifre, A., Malaplate-Armand, C., Lozac'h-Pillot, K., Koziel, V., et al. (2005). Cytosolic phospholipase A2 mediates neuronal apoptosis induced by soluble oligomers of the amyloid-beta peptide. FASEB J. 19, 85-87.

Lin, M. T., and Beal, M. F. (2006). Mitochondrial dysfunction and oxidative stress in neurodegenerative diseases. Nature 443, 787-795. doi: 10.1038 /nature 05292

Mairet-Coello, G., Courchet, J., Pieraut, S., Courchet, V., Maximov, A., and Polleux, F. (2013). The CAMKK2-AMPK kinase pathway mediates the synaptotoxic effects of Abeta oligomers through Tau phosphorylation. Neuron 78, 94-108. doi: 10.1016/j.neuron.2013. 02.003

Manji, H., Kato, T., Di Prospero, N. A., Ness, S., Beal, M. F., Krams, M., et al. (2012). Impaired mitochondrial function in psychiatric disorders. Nat. Rev. Neurosci. 13, 293-307.

Paula-Lima, A. C., Adasme, T., Sanmartin, C., Sebollela, A., Hetz, C., Carrasco, M. A., et al. (2011). Amyloid beta-peptide oligomers stimulate RyR-mediated $\mathrm{Ca} 2+$ release inducing mitochondrial fragmentation in hippocampal neurons and prevent RyR-mediated dendritic spine remodeling produced by BDNF. Antioxid. Redox Signal. 14, 1209-1223. doi: 10.1089/ars. 2010.3287

Paula-Lima, A. C., Brito-Moreira, J., and Ferreira, S. T. (2013). Deregulation of excitatory neurotransmission underlying synapse failure in Alzheimer's disease. J. Neurochem. 126, 191-202. doi: 10.1111/jnc.12304

Qi, X., Disatnik, M. H., Shen, N., Sobel, R. A., and Mochly-Rosen, D. (2011). Aberrant mitochondrial fission in neurons induced by protein kinase $\mathrm{C}$ \{delta\} under oxidative stress conditions in vivo. Mol. Biol. Cell 22, 256-265. doi: 10.1091/mbc.E1006-0551

Querfurth, H. W., and Laferla, F. M. (2010). Alzheimer's disease. N. Engl. J. Med. 362, 329-344 doi: 10.1056/NEJMra0909142

Reese, L. C., and Taglialatela, G. (2011). A role for calcineurin in Alzheimer's disease. Curr. Neuropharmacol. 9, 685-692. doi: 10.2174/157015911798376316

Resende, R., Ferreiro, E., Pereira, C., and Resende De Oliveira, C. (2008). Neurotoxic effect of oligomeric and fibrillar species of amyloidbeta peptide 1-42: involvement of endoplasmic reticulum calcium release in oligomerinduced cell death. Neuroscience 155, 725-737. doi: 10.1016/j.neuroscience.2008.06.036

Sanmartin, C. D., Adasme, T., Hidalgo, C., and Paula-Lima, A. C. (2012). The antioxidant $\mathrm{N}$-acetylcysteine prevents the mitochondrial fragmentation induced by soluble amyloid-beta peptide oligomers. Neurodegener. Dis. 10, 34-37. doi: 10.1159/ 000334901

Silva-Alvarez, C., Arrazola, M. S., Godoy, J. A., Ordenes, D., and Inestrosa, N. C. (2013) Canonical Wnt signaling protects hippocampal neurons from Abeta oligomers: role of non-canonical Wnt-5a/Ca(2+) in mitochondrial dynamics. Front. Cell Neurosci. 7:97. doi: $10.3389 /$ fncel.2013.00097 
Smirnova, E., Griparic, L., Shurland, D. L., and Van Der Bliek, A. M. (2001). Dynamin-related protein Drp1 is required for mitochondrial division in mammalian cells. Mol. Biol. Cell 12, 2245-2256. doi: 10.1091/mbc. 12.8.2245

Toledo, E. M., Colombres, M., and Inestrosa, N. C. (2008). Wnt signaling in neuroprotection and stem cell differentiation. Prog. Neurobiol. 86, 281-296. doi: 10.1016/j.pneurobio.2008. 08.001
Yoon, Y., Galloway, C. A., Jhun, B. S., and Yu, T. (2011). Mitochondrial dynamics in diabetes. Antioxid. Redox Signal. 14, 439-457. doi: 10.1089/ars.2010.3286

Received: 05 July 2013; accepted: 10 July 2013; published online: 30 July 2013.

Citation: Paula-Lima AC and Hidalgo C (2013) Amyloid $\beta$-peptide oligomers, ryanodine receptormediated $\mathrm{Ca}^{2+}$ release, and Wnt-5a/Ca $\mathrm{Ca}^{2+}$ signaling: opposing roles in neuronal mitochondrial dynamics?
Front. Cell. Neurosci. 7:120. doi: 10.3389/fncel. 2013.00120

Copyright (c) 2013 Paula-Lima and Hidalgo. This is an open-access article distributed under the terms of the Creative Commons Attribution License (CC BY). The use, distribution or reproduction in other forums is permitted, provided the original author(s) or licensor are credited and that the original publication in this journal is cited, in accordance with accepted academic practice. No use, distribution or reproduction is permitted which does not comply with these terms. 